Article

\title{
Test Paper for Colorimetric Inspection of Fatty Acids and Edible Oils
}

\author{
Feng Zhang, Xiaojie Wang, Xu Jie and Weili Wei * \\ School of Pharmaceutical Sciences, Chongqing University, Chongqing 401331, China; \\ zhang_feng@cqu.edu.cn (F.Z.); 20141802037@cqu.edu.cn (X.W.); jiexu@cqu.edu.cn (X.J.) \\ * Correspondence: wlwei@cqu.edu.cn
}

Received: 27 August 2018; Accepted: 25 September 2018; Published: 27 September 2018

check for updates

\begin{abstract}
Fatty acids (FAs) are of interest to the areas of food science and medicine because they are important dietary sources of fuel for animals and play important roles in many biological processes. The health effects of FAs are different due to the diversity of olefinic bonds in the alkyl chains including number, position and configuration. However, the discrimination of FAs is difficult from a chemical sensing perspective due to the lack of diversity in terms of functional groups. Until now, only a few chemosensors have been developed for selective sensing of FAs based on their overall shape, however they are still limited in discrimination of FAs with subtle structural differences, moreover, they cannot be used for rapid and in situ inspections. Herein, for the first time, we designed a test paper for in situ colorimetric inspection for FAs based on the combination of the highly selective binding of $\mathrm{Ag}^{+}$to olefinic bonds and $\mathrm{Ag}^{+}$mediated color variation of 3,3',5,5',-tetramethylbenzidine. As a result, the sensor exhibited high sensitivity and good selectivity for five FAs with subtle structural differences. Furthermore, our method described herein was successfully applied to monitor the structural variations of FAs and quality changes in mixture edible hot pot oils with heat treatment in time course. Hence, the test paper presented herein holds great potential in the inspection of fats and edible oils in food industries.
\end{abstract}

Keywords: test paper; colorimetric sensor; fatty acid; edible oil

\section{Introduction}

Fatty acids (FAs) are the primary components of animal fats and vegetable oils, which are important dietary sources of fuel and are required for energy storage, membrane proliferation, and the generation of signaling molecules [1]. FAs are aliphatic monocarboxylic acids with carbon atoms ranging from 4 to 28, which are obtained by the hydrolysis of natural triglycerides, phospholipids, and cholesterol esters. According to the number of their olefinic bond, they are classified into three categories, including saturated fatty acids (SFAs) with no olefinic bond, mono-unsaturated fatty acids (mono-UFAs) with one olefinic bond and poly-unsaturated fatty acids (poly-UFAs) with more than one olefinic bond [2]. In nature, UFAs generally have cis configurations, the opposed trans-UFAs (TUFAs) naturally present in ruminant adipose tissue and related dairy products. In food production, liquid cis-UFA (CUFA) esters such as vegetable oils are hydrogenated or partially hydrogenated to produce SFAs or TUFAs, which are more stable and easier to store and use [3]. Thus, the SFAs and TUFAs are widely produced and used in the food industry such as for the production of margarine, snack foods, baked foods and frying fast foods in restaurants [4]. However, extensive experimental and observational data indicate that excessive use of SFAs and TUFAs can easily lead to cardiovascular and related diseases [5-7]. According to world health organization (WHO) estimates, the intake of TUFAs leads to more than 500,000 deaths of people from cardiovascular related diseases every year [8]. In order to protect human health, WHO enacted a plan named REPLACE in 14 May 2018, which is a stipulation to eliminate the industrially-produced TUFAs in the global food industry [8]. 
Therefore, the approaches to determine FAs profile in food industries are important in order to correct nutrition labeling and control of labeling authenticity, which is of great significance to the implementation of the plan of REPLACE.

The structures of FAs are diversity, because the length (carbon number) and unsaturation degree (olefinic bond number) of alkyl chains, position and configuration (cis/trans) of the olefinic bond in FAs are different. The chemical discrimination of FAs is difficult, because they lack special functional groups other than the hydrophobic alkyl chain and carboxyl group. Currently, the most used methods for the determination of FAs are based on gas chromatography (GC) or liquid chromatography (LC) coupling with mass spectrometry (MS) analysis [9-11]. However, the GC/LC-MS techniques suffer from some drawbacks, such as being time-consuming, expensive, operationally complex and relying on sophisticated instrumentation that cannot be used for rapid and in situ analysis. Moreover, a variety of regio- and stereoisomers can exist for FAs, posing a challenge for MS based analyses. Chemosensors have been widely used in various fields because of their rapid, facile and convenient features, and these features just make up for the inadequacies of the GC/LC-MS related techniques. Until now, only a few colorimetric and fluorimetric chemosensors have been developed for selective sensing of FAs based on their overall shape [12,13]. The main capability of these chemosensors is discrimination of mono-CUFAs (with bent alkyl chain) from mono-TUFAs and SFAs (with linear alkyl chains), but they do not show promise in differentiating poly-UFAs and SFAs. Therefore, a portable sensing method for in situ inspection of FAs with different degree of unsaturation, position of olefins, and the configuration of the olefins is urgent but difficult.

It is well known that silver ion $\left(\mathrm{Ag}^{+}\right)$can complex with olefinic bonds reversibly [14]. The stabilities of $\mathrm{Ag}^{+}$-olefin complexes are highly dependent on the properties of olefins that can usually be divided into two groups, namely steric (chain length, cis/trans isomers and number of olefinic bonds) and electronic (conjugation and electron cloud density) properties [15]. Thus, $\mathrm{Ag}^{+}$chromatography has been widely used for the separation of unsaturated compounds with subtle structural differences such as FAs and sterols [16-19]. However, a FAs sensor based on the selective complexation between $\mathrm{Ag}^{+}$and olefinic bonds has never been explored. Interestingly, the colorless 3,3',5,5',-tetramethylbenzidine (TMB) can be oxidized by $\mathrm{Ag}^{+}$and turn blue, and the color intensity is positively correlated with the concentration of $\mathrm{Ag}^{+}$[20-22]. When combining the highly selective binding ability of $\mathrm{Ag}^{+}$to olefinic bonds and $\mathrm{Ag}^{+}$ mediated color variation of TMB, a colorimetric sensing method to inspection of FAs is possibly designed.

Recently, test paper-based colorimetric sensors have been widely applicated in various fields such as disease diagnosis [23-26], environmental monitoring [27,28] and food safety inspection [29,30] due to their simplicity, disposability, economical efficiency and minimal samples requirement [31]. More importantly, they are easier to use in in situ inspections. According to the principle of paper-based colorimetric sensing, some specific reagents are necessary to develop color intensity and/or hue correlates with types and concentration of analytes [32]. Herein, considering the $\mathrm{Ag}^{+}$mediated color variation of TMB and selective binding of $\mathrm{Ag}^{+}$with olefinic bonds, we propose a test paper for FAs inspection (Scheme 1). By mixing $\mathrm{Ag}^{+}$with FAs in a solution, a part of $\mathrm{Ag}^{+}$could form $\mathrm{Ag}^{+}-\mathrm{FAs}$ complexes and the remnant part is free $\mathrm{Ag}^{+}$ions. The free $\mathrm{Ag}^{+}$could further oxidize TMB and develop blue colors. The proportion of free $\mathrm{Ag}^{+}$is dependent on the concentration and type of FAs. Therefore, by taking advantage of the complexation difference of $\mathrm{Ag}^{+}$to olefinic bonds of FAs, we successfully identified five types of model FAs with subtle structural differences. Using the approach described herein, the structural variation of FAs with heat treatment can be successfully monitored. Furthermore, the quality changes of mixture FAs in edible hot pot oils with heat treatment were successfully monitored by the test paper presented herein. 


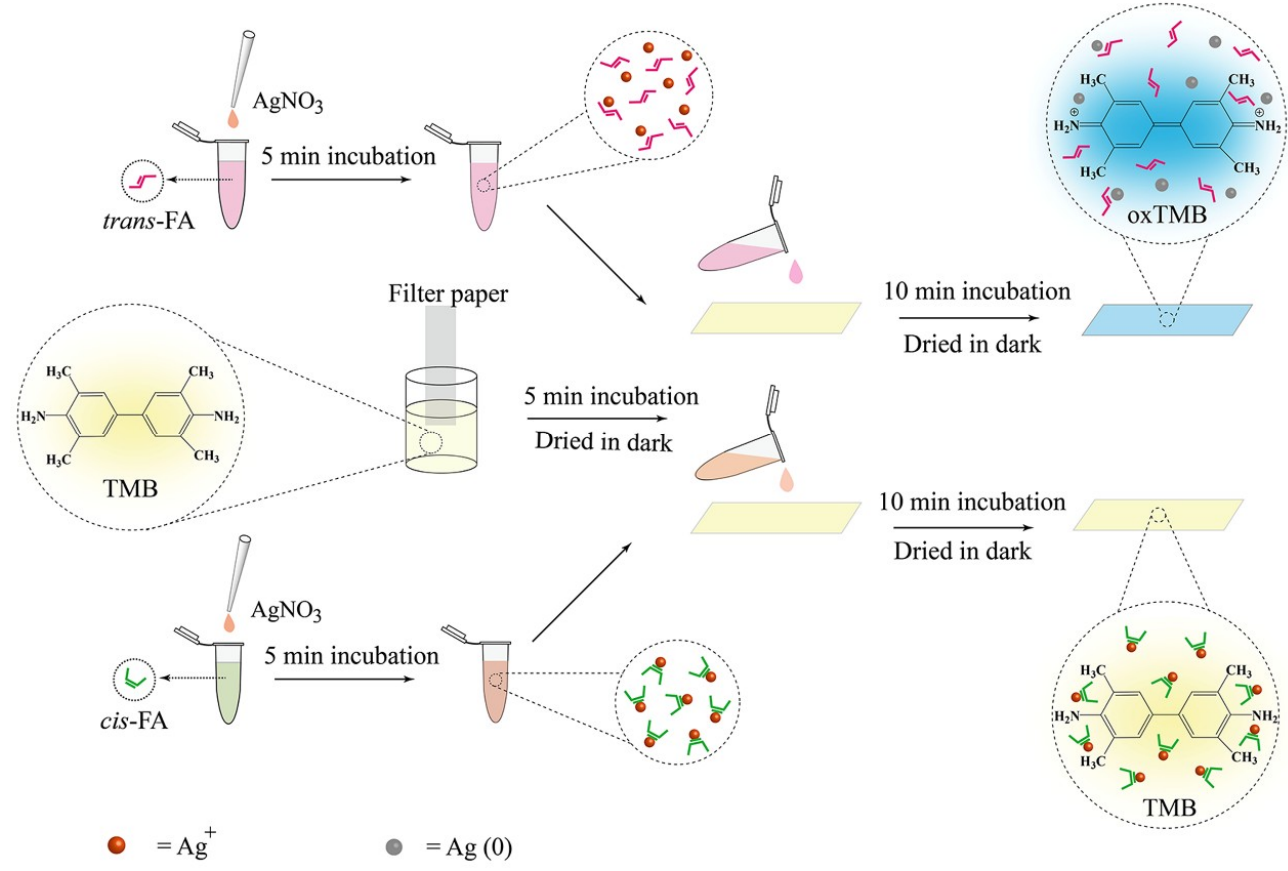

Scheme 1. Illustration of the mechanism of test paper for colorimetric inspection of FAs according to the color changes of TMB induced by $\mathrm{Ag}^{+}$oxidation.

\section{Materials and Methods}

\subsection{Materials}

Stearic acid, oleic acid, linoleic acid, linolenic acid, elaidic acid, silver nitrate $\left(\mathrm{AgNO}_{3}\right)$, sodium acetate and acetic acid were obtained from Aladdin Reagent Database Inc. (Shanghai, China) without further purification. TMB was purchased from Sigma-Aldrich and dissolved in ethanol with concentration of $50 \mathrm{mM}$ as stock solution, further dilution was completed by using sodium acetate-acetic acid $(\mathrm{NaAc})$ buffer solution. Milli-Q water $(18 \mathrm{M} \Omega . \mathrm{cm})$ from a Millipore system was used in our experiments.

\subsection{FAs Preparation}

Stearic acid, oleic acid, linoleic acid, linolenic acid, elaidic acid were dissolved in ethanol with concentration of $10 \mathrm{mM}$ as stock solution and diluted to different concentration for further use. For oleic acid heating experiment, oleic acid was heated at $180^{\circ} \mathrm{C}$ with vigorous stirring and collected at $0,2,4$, $6,8 \mathrm{~h}$ respectively. Then the collected samples dissolved in ethanol for further colorimetric sensing. To prepare the real samples, hot pot oil was heated at $180^{\circ} \mathrm{C}$ and collected at $0,2,4,6,8 \mathrm{~h}$ respectively. Then $1 \mathrm{~mL}$ of the collected oils mixed with $5 \mathrm{~mL} n$-hexane respectively, after $10 \mathrm{~min}$, the supernatant of the mixture was separated and $n$-hexane was removed with a rotary evaporator, and the remaining oils were collected for further colorimetric sensing.

\subsection{Colorimetric Sensing of FAs}

The experiments were performed in $0.2 \mathrm{M} \mathrm{NaAc}$ buffer solution with different $\mathrm{pH}$ range from 4.0-6.5. A $10 \mu \mathrm{L}$ of FAs was added to $100 \mu \mathrm{L} \mathrm{AgNO}_{3}$ solution with final concentration range from $0.05-0.20 \mathrm{mM}$, and then $200 \mu \mathrm{L}$ of TMB with final concentration range from $0.1-0.5 \mathrm{mM}$ was added to the mixture and reacted at room temperature for 5-30 min. The UV-vis absorption spectra and digital photos of the resulting solutions were recorded on a Varian CARY 50 spectrophotometer (Agilent Technologies Inc., Santa Clara, CA, USA) and Canon 500D digital camera (Canon Inc., Tokyo, Japan) respectively. 


\subsection{Colorimetric Sensing for FAs by Test Paper}

To prepare a paper-based device for FAs inspection, filter papers were cut into $0.4 \mathrm{~cm} \times 2.5 \mathrm{~cm}$, and immersed in TMB $(0.3 \mathrm{mM})$, after $5 \mathrm{~min}$ incubation, filter papers were taken out, dried with nitrogen in dark and stored in a dryer without light for further use. In order to achieve FAs inspection, $\mathrm{AgNO}_{3}(0.175 \mathrm{mM})$ was firstly added in analyte FAs and incubated for $5 \mathrm{~min}$; then $100 \mu \mathrm{L}$ of the mixture was added to the as prepared paper-based device and incubated for 10 min in dark; finally, the colored papers dried with nitrogen in dark. After 10 min stabilization in dark in an ambient room, the resulting filter papers were recorded by digital camera.

\section{Results and Discussion}

To demonstrate the $\mathrm{Ag}^{+}-\mathrm{TMB}$ sensing system could be applied to inspect of FAs, we firstly implemented some verification experiments, and the results are shown in Figure 1. The TMB alone exhibits no blue color and absorbance peaks (curve a and inset Figure 1a). When $\mathrm{Ag}^{+}$was added to $\mathrm{TMB}$, an obvious blue color with strong absorbance peaks centered at $652 \mathrm{~nm}$ was observed (curve $\mathrm{b}$ and inset Figure $1 \mathrm{~b}$ ), which could be attributed to the direct oxidation of TMB by $\mathrm{Ag}^{+}$, for there is no other reducing agent in this system. There was no blue color and absorbance peaks when oleic acid was added to TMB (curve $c$ and inset Figure 1c), suggesting that the oleic acid alone has no effect on the oxidation of TMB. Significantly, when the mixture of oleic acid and $\mathrm{Ag}^{+}$was added to TMB (curve $\mathrm{d}$ and inset Figure 1d), the blue color of oxidized TMB faded and its absorbance at $652 \mathrm{~nm}$ was decreased; because $\mathrm{Ag}^{+}$complexes with the olefinic bonds of oleic acid, thus the content of free $\mathrm{Ag}^{+}$is reduced and finally weakened the oxidation of TMB. According to a previous report [33], the strong complexation between $\mathrm{Ag}^{+}$and FAs is attributed to the formation of $\sigma$-bonds and $\pi$-bonds between olefinic bonds and $\mathrm{Ag}^{+}$. Therefore, the results of Figure 1 prove the feasibility of the $\mathrm{Ag}^{+}-\mathrm{TMB}$ sensing system in the inspection of FAs.

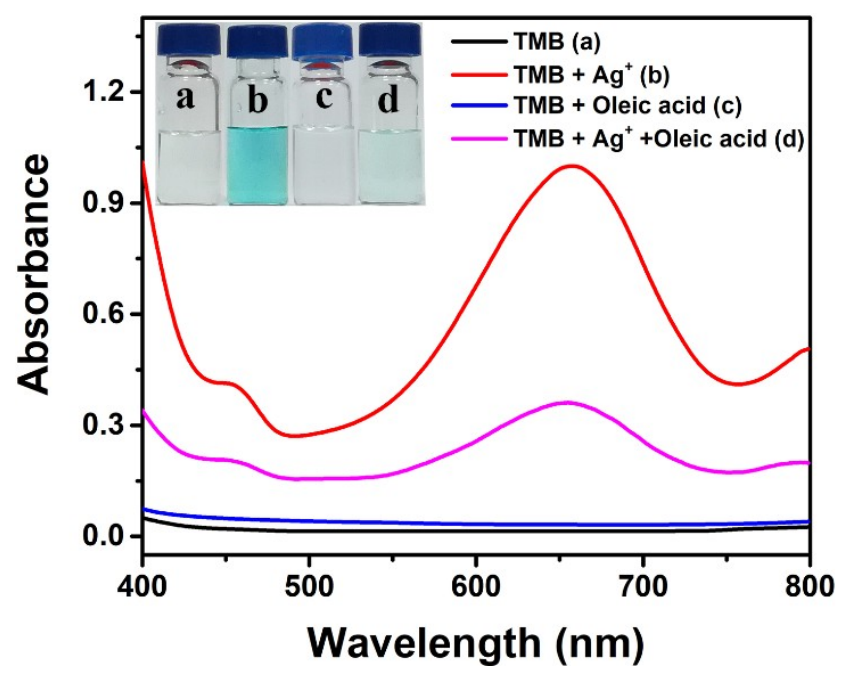

Figure 1. UV-vis absorption spectra of $0.3 \mathrm{mM} \mathrm{TMB}(\mathrm{a})$ without $0.175 \mathrm{mM} \mathrm{Ag}^{+}$and $1 \mu \mathrm{M}$ oleic acid, (b) with $0.175 \mathrm{mM} \mathrm{Ag}^{+}$and without $1 \mu \mathrm{M}$ oleic acid (c) with $1 \mu \mathrm{M}$ oleic acid and without $0.175 \mathrm{mM}$ $\mathrm{Ag}^{+}$, (d) with $0.175 \mathrm{mM} \mathrm{Ag}^{+}$and $1 \mu \mathrm{M}$ oleic acid. The inset shows the corresponding digital photo.

In order to realize effective colorimetric sensing, we optimized experimental conditions such as incubation time, $\mathrm{pH}$, concentration of $\mathrm{AgNO}_{3}$ and TMB. We chose the parameter $\triangle A$ as a criterion for optimization; $\triangle A=A_{0}-A, A_{0}$ and $A$ represent the absorbance of $\mathrm{Ag}^{+}-\mathrm{TMB}$ system at $652 \mathrm{~nm}$ in the absence and presence of oleic acid respectively. As shown in Figure 2a, the values of $\Delta A$ are distinct among different incubation time ranging from 5-30 min, and $10 \mathrm{~min}$ incubation obtained the highest value. Increasing the time has no effect on the increasing of $\Delta A$, as a result, $10 \mathrm{~min}$ is appropriate for the experiments followed. 

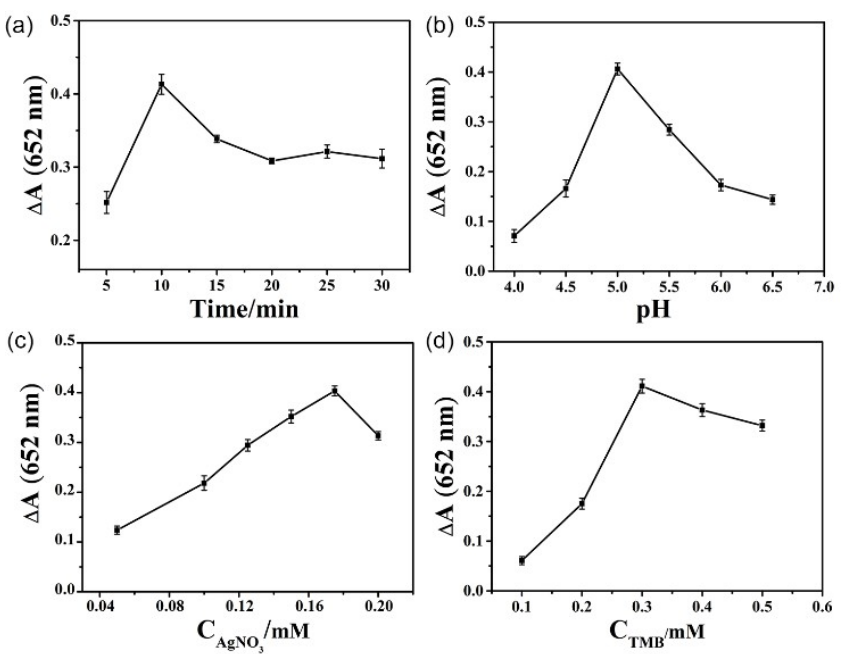

Figure 2. (a) Effect of incubation time on the $\Delta A$ (0.2 M NaAc buffer, pH 5.0, $0.3 \mathrm{mM} \mathrm{TMB}, 0.175 \mathrm{mM}$ $\mathrm{AgNO}_{3}$ and $500 \mathrm{nM}$ oleic acid). (b) Effect of $\mathrm{pH}$ on the $\triangle A$ (0.2 M NaAc buffer, $0.3 \mathrm{mM} \mathrm{TMB}, 0.175 \mathrm{mM}$ $\mathrm{AgNO}_{3}, 500 \mathrm{nM}$ oleic acid and $10 \mathrm{~min}$ incubation). (c) Effect of $\mathrm{AgNO}_{3}$ concentration on the $\Delta A$ (0.2 M NaAc buffer, pH 5.0, $0.3 \mathrm{mM}$ TMB, $500 \mathrm{nM}$ oleic acid and $10 \mathrm{~min}$ incubation). (d) Effect of TMB concentration on the $\Delta A\left(0.2 \mathrm{M} \mathrm{NaAc}\right.$ buffer, $\mathrm{pH} 5.0,0.175 \mathrm{mM} \mathrm{AgNO}_{3}, 500 \mathrm{nM}$ oleic acid and 10 min incubation).

According to a previous report [21], the $\mathrm{pH}$ affected the oxidation capacity of $\mathrm{Ag}^{+}$, therefore we investigated the effect of $\mathrm{pH}$ on the $\mathrm{Ag}^{+}-\mathrm{TMB}$ sensing system. We adopted a $0.2 \mathrm{M} \mathrm{NaAc}$ buffer with $\mathrm{pH}$ range from 4.0-6.5 to determine the optimum. As shown in Figure $2 \mathrm{~b}, \Delta A$ increased gradually when the $\mathrm{pH}$ increased from 4.0 to 5.0 , and when the $\mathrm{pH}$ was greater than 5.0 the $\Delta A$ decreased gradually, therefore, we chose $\mathrm{pH} 5.0$ for the FAs sensing experiments.

Finally, the concentration of TMB and $\mathrm{AgNO}_{3}$ were optimized. As shown in Figure 2c,d, the too high or too low concentration of $\mathrm{TMB}$ and $\mathrm{AgNO}_{3}$ are not appropriate for FAs sensing. On the one hand, the higher concentration of TMB and $\mathrm{AgNO}_{3}$ needs higher concentrations of FAs to produce the recognizable color changes, which reduces the sensitivity of the sensing system. On the other hand, the low concentration of $\mathrm{TMB}$ and $\mathrm{AgNO}_{3}$ makes the low absorbance of oxidized TMB which introduces the larger experimental error. When the concentration of $\mathrm{TMB}$ and $\mathrm{AgNO}_{3}$ are $0.3 \mathrm{mM}$ and $0.175 \mathrm{mM}$, the highest $\triangle A$ are obtained respectively. Therefore, we chose $0.3 \mathrm{mM}$ of TMB and $0.175 \mathrm{mM}$ of $\mathrm{AgNO}_{3}$ for the next FAs sensing experiments.

To verify the sensitivity and concentration-dependent response of $\mathrm{Ag}^{+}-\mathrm{TMB}$ system for FAs, the effect of 0 to $6 \mu \mathrm{M}$ oleic acid on the color change of $\mathrm{Ag}^{+}$-TMB system was investigated. As shown in the inset of Figure 3a, under the optimal experimental conditions, the color changes of the $\mathrm{Ag}^{+}-\mathrm{TMB}$ system induced by the variation of oleic acid concentration can be clearly visualized. The dark blue color of $\mathrm{Ag}^{+}-\mathrm{TMB}$ system is gradually weakened to light blue with the increasing of oleic acid concentration. Meanwhile, the corresponding absorbance of $\mathrm{Ag}^{+}-\mathrm{TMB}$ system at $652 \mathrm{~nm}$ is decreasing (Figure 3a) as the oleic acid concentration is increasing. Correspondingly, $\Delta A$ with the increasing concentration of oleic acid were investigated (Figure $3 b$ ). It is obviously seen that $\Delta A$ increased gradually with the increasing of oleic acid concentration, and there is no obvious increase observed when the concentration of oleic acid is up to $2 \mu \mathrm{M}$. In the range of $0-1 \mu \mathrm{M}, \Delta A$ increased linearly with increasing oleic acid concentration (inset of Figure $3 \mathrm{~b}$ ), and the equation fitted as $\Delta A=0.01+0.63 C$ (C is the concentration of oleic acid), with the corresponding $R^{2}=0.989$. 

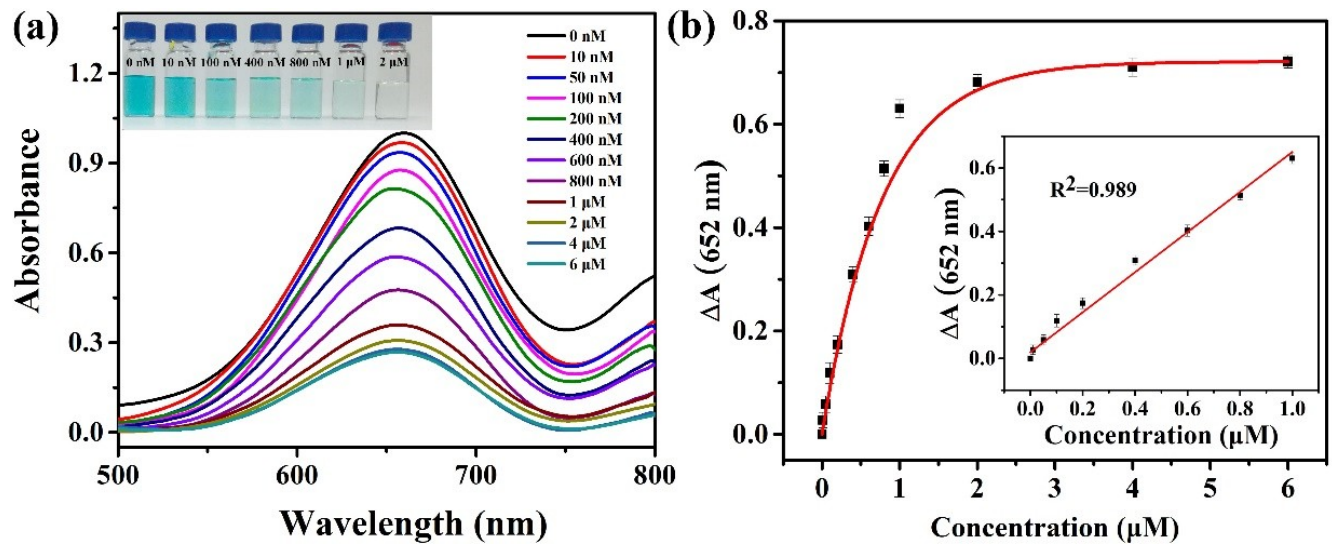

Figure 3. (a) Absorption spectra (inset is digital photo) of $\mathrm{Ag}^{+}-\mathrm{TMB}$ system in the presence of different concentrations of oleic acid ( 0 to $6 \mu \mathrm{M}$, from top to bottom); (b) Plots of $\Delta A$ versus different concentrations of oleic acid ranging from 0 to $6 \mu \mathrm{M}$ (inset is the linear relationship between $\Delta A$ and the concentration of oleic acid from 0 to $1 \mu \mathrm{M}$ ). Experimental conditions: $0.2 \mathrm{M} \mathrm{NaAc}$ buffer $(\mathrm{pH}=5.0)$, $0.3 \mathrm{mM}$ of $\mathrm{TMB}$ and $0.175 \mathrm{mM}$ of $\mathrm{AgNO}_{3}$, incubation time is $10 \mathrm{~min}$. The error bars represented standard deviations based on three independent measurements.

In order to demonstrate the selectivity of the $\mathrm{Ag}^{+}-\mathrm{TMB}$ system, five FAs including stearic acid (SFAs), oleic acid (mono-CUFAs), linoleic acid (poly-CUFAs), linolenic acid (poly-CUFAs) and elaidic acid (TUFAs) with different unsaturation degrees and configuration of the olefinic bonds (Figure 4a) were investigated. Figure $4 \mathrm{~b}$ is the digital photo of $\mathrm{Ag}^{+}-\mathrm{TMB}$ sensing system towards the above five FAs, and Figure $4 \mathrm{c}$ is the corresponding absorption spectra. The number of 0 (blank) represents $\mathrm{Ag}^{+}-\mathrm{TMB}$ system with the addition of equal volume of ethanol without any FAs addition as the control experiment, and numbers 1-5 represent the above five FAs respectively. As shown in Figure $4 \mathrm{~b}$, five FAs displayed distinct colors ranging from dark blue to colorless, and the five types of FAs were readily distinguished from blank by the naked eye except for stearic acid (1). Because stearic acid has no olefinic bond, it cannot complex with $\mathrm{Ag}^{+}$and produce color change. A similar result is observed in Figure $4 \mathrm{c}$, that is, the addition of stearic acid has almost no effect on the change of absorption spectrum of $\mathrm{Ag}^{+}-\mathrm{TMB}$ system. For oleic acid (2), linoleic acid (3) and linolenic acid (4), they are all CUFAs but with different numbers of olefinic bonds: 1,2 and 3 respectively. With the number of olefinic bonds increasing, the color changed from dark blue to colorless, and the corresponding absorbance of $\mathrm{Ag}^{+}-\mathrm{TMB}$ system at $652 \mathrm{~nm}$ gradually decreased. The reason for this is that the complexation ability of FAs with $\mathrm{Ag}^{+}$increased with the number of olefinic bond increasing. Linolenic acid shows the lowest absorption at $652 \mathrm{~nm}$ and almost colorless, for it has 3 olefinic bonds and complexes with $\mathrm{Ag}^{+}$more easily than other two FAs. As for different configurations of FAs, for example, in the case of oleic acid (2) and elaidic acid (5) which only have one olefinic bond at same position but with different configurations, the result of colorimetric sensing is distinct. Elaidic acid exhibits darker blue and higher absorption at $652 \mathrm{~nm}$ compared with oleic acid. Because the complexation between $\mathrm{Ag}^{+}$and trans-olefinic bond is weaker than cis-configuration, therefore, the degree of TMB oxidation caused by trans- is more acute than cis-configuration. As a result, the color of $\mathrm{Ag}^{+}-\mathrm{TMB}$ system in the presence of oleic acid is lighter than the presence of elaidic acid. 
(a)
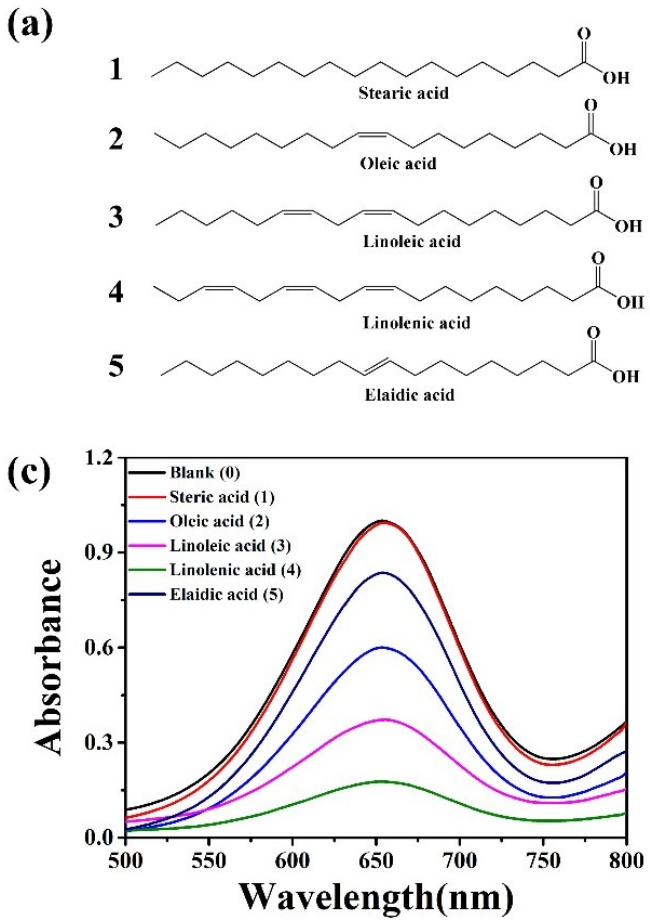

(b)

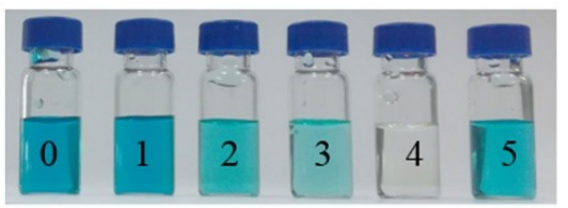

(d)

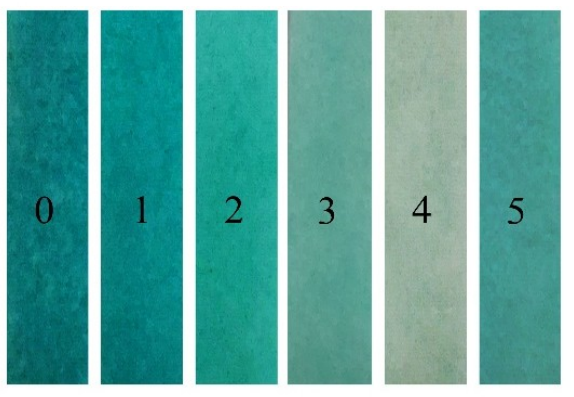

Figure 4. (a) Molecular structures of five FAs; (b) digital photo and (c) absorption spectra of $\mathrm{Ag}^{+}-\mathrm{TMB}$ sensing system towards five FAs (FAs concentration: $500 \mathrm{nM}$ ); (d) test papers towards five FAs. The meaning of numbers: 0 (blank), 1 (steric acid), 2 (oleic acid), 3 (linoleic acid), 4 (linolenic acid), 5 (elaidic acid).

Next, we designed a test paper for colorimetric sensing of FAs based on the proposed $\mathrm{Ag}^{+}-\mathrm{TMB}$ sensing system to improve the portability and disposability of this sensing system. As shown in Figure $4 \mathrm{~d}$, the paper-based devices exhibit distinct colors toward the above five types of FAs and could be easily distinguished from blank (0) except for steric acid (1). CUFAs including oleic acid (2), linoleic acid (3) and linolenic acid (4) shows the gradual fading blue color for their number of olefinic bond are increasing. As for configurational identification, the elaidic acid (5) shows darker blue than oleic acid (2), for TUFAs has lower ability to complex with $\mathrm{Ag}^{+}$than CUFAs. Thus, the results indicate that the delicately designed test paper shows good selectivity for different types of FAs; and it's worth noting that the preparation processes of test paper were very simple, which could be widely used in in situ inspection of FAs.

Furthermore, the test paper could be used in monitoring of FAs structural variations, and we took oleic acid as example to illustrate. According to a previous report [34], heating could induce FAs variation in terms of unsaturation degree and generation of harmful trans-configurations; thus, we implemented experiments to monitor the structural variation of oleic acid by the proposed approach. As shown in the inset of Figure 5a, oleic acid without heating $(0 \mathrm{~h})$ exhibits a very light blue color, while when the heating time increased from 0 to $8 \mathrm{~h}$, the color of $\mathrm{Ag}^{+}-\mathrm{TMB}$ solution is gradually deepened to dark blue and the absorption of the sensing system at $652 \mathrm{~nm}$ is gradually increased. Correspondingly, the test paper shows the similar results (Figure $5 b$ ). The color changes of the sensor are ascribed to the unsaturation and configuration variation of oleic acid induced by heating. 

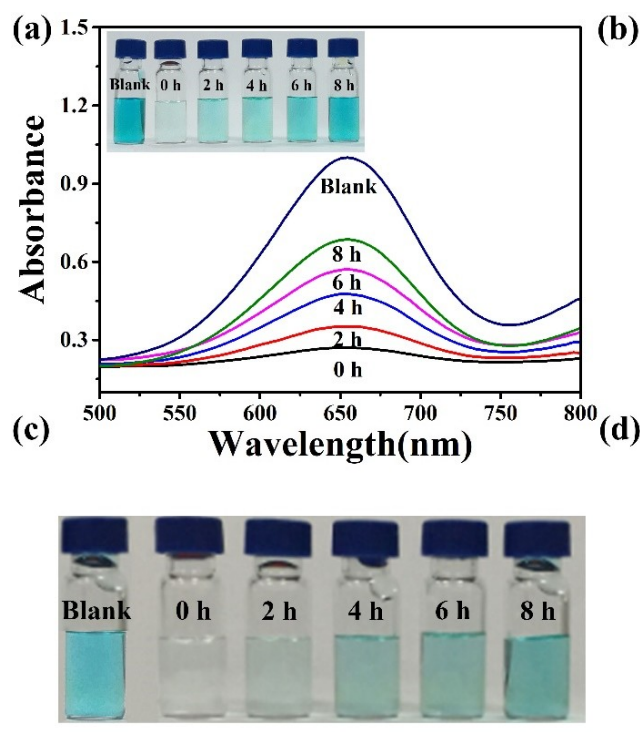

(b)
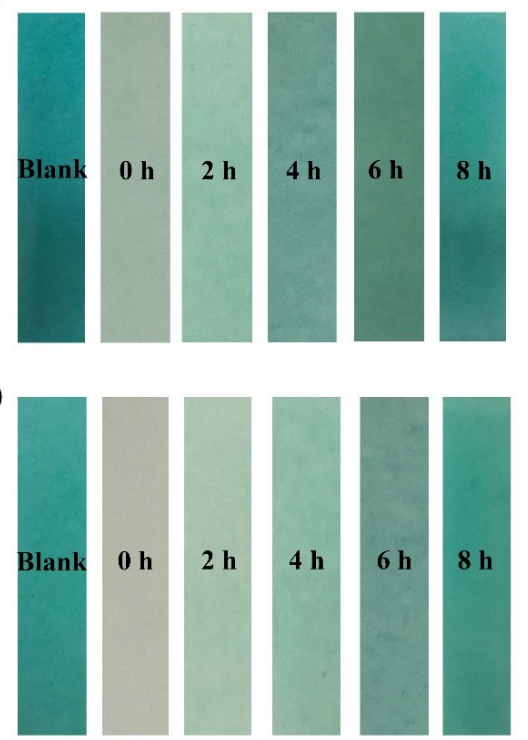

Figure 5. (a) Absorption spectra (inset is digital photo) of $\mathrm{Ag}^{+}-\mathrm{TMB}$ sensing system and (b) test papers toward oleic acid samples with heat treatment at $180{ }^{\circ} \mathrm{C}$ for different times; (c) digital photo of $\mathrm{Ag}^{+}-\mathrm{TMB}$ sensing system and (d) test papers toward hot pot oils with heat treatment at $180{ }^{\circ} \mathrm{C}$ for different time.

In order to prove the feasibility of the test paper for the in situ inspection of complex mixture FAs, we profiled the quality changes of edible hot pot oils with heat treatment based on the method described herein. Edible oils are a very important source of FAs, and usually suffered from variations of unsaturation degree and configuration, which occurs when fresh edible oils are heated at high temperatures during various food preparations [35]. Illegal gutter oils are refined second-hand oils which is detrimental to people's health because their quality have been declined, but it is common to use these oils in the commercial food industry for maximized profits. Therefore, the inspection of the quality of edible oils is significant. As a very famous special food in China, hot pot is very popular there, and the oils used for this cuisine suffered continuous heating during the process of eating. There are many reported food safety incidents regarding second-hand oils being used in hot pot, therefore the quality monitoring of the hot pot oils is very important. Soybean oil is a commonly used edible oil in hot pot, which mainly composed of CFAs (ca. 81\%), with saturated FAs as minor components (ca. 18\%) [36]. In our work, we monitored the quality changes of soybean oil under continuous heating with different times. As shown in Figure $5 \mathrm{c}$, the original oil $(0 \mathrm{~h})$ without heating is almost colorless, and with the increased heating time from 0 to $8 \mathrm{~h}$, the color of the sensing system gradually turns dark blue. In the paper-based sensing results (Figure $5 \mathrm{~d}$ ), the original oil $(0 \mathrm{~h})$ shows the color of filter paper, and the color of paper gradually changed to dark blue with as the heating time increased. The color changes were mainly attributed to the variation of unsaturation degree and configuration of FAs, which lower the complexation ability of hot pot oil with $\mathrm{Ag}^{+}$, thus the adequate free $\mathrm{Ag}^{+}$could oxidize TMB and develop blue colors. These results indicate that the portable and disposable test paper can be used to monitor the changes in oil quality by the naked eye, and the method can be used in in situ safety inspection of edible oils.

\section{Conclusions}

In this work, we proposed a test paper for the colorimetric inspection of FAs with subtle difference in their alkyl chains such as number, position and configuration of olefinic bonds. For the first time, the approach we designed herein could discriminate FAs rely on the highly selective binding of $\mathrm{Ag}^{+}$to olefinic bonds in FAs rather than the shape of alkyl chain (bent or linear). Based on the $\mathrm{Ag}^{+}$mediated color variation of TMB, the test paper achieved colorimetric discrimination of five types of model FAs 
including stearic acid, oleic acid, linoleic acid, linolenic acid, and elaidic acid. Furthermore, the test paper was successfully applied to monitor the structural variations of oleic acid with heat treatment. Significantly, the quality changes of mixture edible hot pot oils with heat treatment was successfully monitored by the sensor. Thus, the facile, economic, portable and disposable test paper for FAs holds great potential in in situ food safety inspection.

Author Contributions: Conceptualization, W.W.; Data curation, X.J.W.; Formal analysis, F.Z.; Writing—original draft, X.J.; Writing-review \& editing, W.W.

Acknowledgments: Fundamental Research Funds for the Central Universities (No. 106112017CDJXSYY0001) financially supported this work.

Conflicts of Interest: The authors declare no conflict of interest.

\section{References}

1. Currie, E.; Schulze, A.; Zechner, R.; Walther, T.C.; Farese, R.V. Cellular Fatty Acid Metabolism and Cancer. Cell Metab. 2013, 18, 153-161. [CrossRef] [PubMed]

2. de Oliveira, M.A.L.; Porto, B.L.S.; Faria, I.D.L.; de Oliveira, P.L.; Barra, P.M.D.; Castro, R.D.C.; Sato, R.T. 20 Years of Fatty Acid Analysis by Capillary Electrophoresis. Molecules 2014, 19, 14094-14113. [CrossRef] [PubMed]

3. Brouwer, I.A.; Wanders, A.J.; Katan, M.B. Effect of Animal and Industrial Trans Fatty Acids on HDL and LDL Cholesterol Levels in Humans-A Quantitative Review. PLoS ONE 2010, 5, e9434. [CrossRef]

4. Hung, W.L.; Hwang, L.S.; Shahidi, F.; Pan, M.H.; Wang, Y.; Ho, C.T. Endogenous formation of trans fatty acids: Health implications and potential dietary intervention. J. Funct. Foods 2016, 25, 14-24. [CrossRef]

5. Willett, W.C.; Stampfer, M.J.; Manson, J.E.; Colditz, G.A.; Speizer, F.E.; Rosner, B.A.; Sampson, L.A.; Hennekens, C.H. Intake of Trans-Fatty-Acids and Risk of Coronary Heart-Disease among Women. Lancet 1993, 341, 581-585. [CrossRef]

6. Oomen, C.M.; Ocke, M.C.; Feskens, E.J.M.; van Erp-Baart, M.A.J.; Kok, F.J; Kromhout, D. Association between trans fatty acid intake and 10-year risk of coronary heart disease in the Zutphen Elderly Study: A prospective population-based study. Lancet 2001, 357, 746-751. [CrossRef]

7. Zong, G.; Li, Y.P.; Wanders, A.J.; Alssema, M.; Zock, P.L.; Willett, W.C.; Hu, F.B.; Sun, Q. Intake of individual saturated fatty acids and risk of coronary heart disease in US men and women: Two prospective longitudinal cohort studies. BMJ 2016, 355, i5796. [CrossRef] [PubMed]

8. World Health Organization. WHO Plan to Eliminate Industrially-Produced Trans-Fatty Acids from Global Food Supply. Available online: http:/ / www.who.int/news-room/releases/3 (accessed on 14 May 2018).

9. Petrovic, M.; Kezic, N.; Bolanca, V. Optimization of the GC method for routine analysis of the fatty acid profile in several food samples. Food Chem. 2010, 122, 285-291.

10. Lacaze, J.P.C.L.; Stobo, L.A.; Turrell, E.A.; Quilliam, M.A. Solid-phase extraction and liquid chromatographymass spectrometry for the determination of free fatty acids in shellfish. J. Chromatogr. A 2007, 1145, 51-57. [CrossRef] [PubMed]

11. Rigano, F.; Albergamo, A.; Sciarrone, D.; Beccaria, M.; Purcaro, G.; Mondello, L. Nano Liquid Chromatography Directly Coupled to Electron Ionization Mass Spectrometry for Free Fatty Acid Elucidation in Mussel. Anal. Chem. 2016, 88, 4021-4028. [CrossRef] [PubMed]

12. Shorthill, B.J.; Avetta, C.T.; Glass, T.E. Shape-selective sensing of lipids in aqueous solution by a designed fluorescent molecular tube. J. Am. Chem. Soc. 2004, 126, 12732-12733. [PubMed]

13. Cho, Y.S.; Ma, D.H.; Ahn, K.H. Shape-selective, stoichiometric sensing of fatty acids with a mixed polydiacetylene liposome. J. Mater. Chem. C 2016, 4, 2871-2876. [CrossRef]

14. Hong, S.U.; Jin, J.H.; Won, J.; Kang, Y.S. Polymer-salt complexes containing silver ions and their application to facilitated olefin transport membranes. Adv. Mater. 2000, 12, 968-971. [CrossRef]

15. Hartley, F.R. Thermodynamic Data for Olefin and Acetylene Complexes of Transition-Metals. Chem. Rev. 1973, 73, 163-190. [PubMed]

16. Ruan, B.F.; Shey, J.; Gerst, N.; Wilson, W.K.; Schroepfer, G.J. Silver ion high pressure liquid chromatography provides unprecedented separation of sterols: Application to the enzymatic formation of cholesta-5,8-dien-3 beta-ol. Proc. Natl. Acad. Sci. USA 1996, 93, 11603-11608. [CrossRef] [PubMed] 
17. Momchilova, S.; Nikolova-Damyanova, B. Silver ion HPLC of p-methoxyphenacyl derivatives of unsaturated fatty acids. II. Chain length vs. double bond position. J. Liq. Chromatogr. Relat. Technol. 2000, 23, 2317-2325.

18. Stolyhwo, A.; Rutkowska, J. An Improved Silver Ion HPLC Combined with Capillary Gas Chromatography of cis/trans Fatty Acids in Alimentary Fats and Human Milk Fat. Food Anal. Methods 2013, 6, 457-469.

19. Adlof, R. Analysis of triacylglycerol and fatty acid isomers by low-temperature silver-ion high performance liquid chromatography with acetonitrile in hexane as solvent: Limitations of the methodology. J. Chromatogr. A 2007, 1148, 256-259. [PubMed]

20. Liu, S.; Tian, J.Q.; Wang, L.; Sun, X.P. Highly sensitive and selective colorimetric detection of Ag(I) ion using 3,3',5, $5^{\prime}$,-tetramethylbenzidine (TMB) as an indicator. Sens. Actuators B 2012, 165, 44-47. [CrossRef]

21. Ni, P.J.; Sun, Y.J.; Dai, H.C.; Jiang, S.; Lu, W.D.; Wang, Y.L.; Li, Z.; Li, Z. Colorimetric assay for acetylcholinesterase and inhibitor screening based on the Ag [I] ion-3,3',5,5'-tetramethylbenzidine (TMB). Sens. Actuators B 2016, 226, 104-109. [CrossRef]

22. Gonzalez-Fuenzalida, R.A.; Moliner-Martinez, Y.; Gonzalez-Bejar, M.; Molins-Legua, C.; Verdu-Andres, J.; Perez-Prieto, J.; Campins-Falco, P. In Situ Colorimetric Quantification of Silver Cations in the Presence of Silver Nanoparticles. Anal. Chem. 2013, 85, 10013-10016. [CrossRef] [PubMed]

23. Lopez-Marzo, A.M.; Merkoci, A. Paper-based sensors and assays: A success of the engineering design and the convergence of knowledge areas. Lab Chip 2016, 16, 3150-3176. [CrossRef] [PubMed]

24. Teengam, P.; Siangproh, W.; Tuantranont, A.; Vilaivan, T.; Chailapakul, O.; Henry, C.S. Multiplex Paper-Based Colorimetric DNA Sensor Using Pyrrolidinyl Peptide Nucleic Acid-Induced AgNPs Aggregation for Detecting MERS-CoV, MTB, and HPV Oligonucleotides. Anal. Chem. 2017, 89, 5428-5435. [CrossRef] [PubMed]

25. Tsai, T.T.; Huang, C.Y.; Chen, C.A.; Shen, S.W.; Wang, M.C.; Cheng, C.M.; Chen, C.F. Diagnosis of Tuberculosis Using Colorimetric Gold Nanoparticles on a Paper-Based Analytical Device. ACS Sens. 2017, 2, 1345-1354. [CrossRef] [PubMed]

26. Parolo, C.; Merkoci, A. Paper-based nanobiosensors for diagnostics. Chem. Soc. Rev. 2013, 42, 450-457. [CrossRef] [PubMed]

27. Ju, Q.; Noor, M.O.; Krull, U.J. Paper-based biodetection using luminescent nanoparticles. Analyst 2016, 141, 2838-2860. [CrossRef] [PubMed]

28. Rull-Barrull, J.; d'Halluin, M.; Le Grognec, E.; Felpin, F.X. A paper-based biomimetic device for the reduction of $\mathrm{Cu}$ (II) to $\mathrm{Cu}$ (I)-application to the sensing of $\mathrm{Cu}$ (II). Chem. Commun. 2016, 52, 6569-6572. [CrossRef] [PubMed]

29. Tseng, S.Y.; Li, S.Y.; Yi, S.Y.; Sun, A.Y.; Gao, D.Y.; Wan, D.H. Food Quality Monitor: Paper-Based Plasmonic Sensors Prepared Through Reversal Nanoimprinting for Rapid Detection of Biogenic Amine Odorants. ACS Appl. Mater. Interfaces 2017, 9, 17307-17317. [CrossRef] [PubMed]

30. Zhang, Y.L.; Zuo, P.; Ye, B.C. A low-cost and simple paper-based microfluidic device for simultaneous multiplex determination of different types of chemical contaminants in food. Biosens. Bioelectron. 2015, 68, 14-19. [CrossRef] [PubMed]

31. Meredith, N.A.; Quinn, C.; Cate, D.M.; Reilly, T.H.; Volckens, J.; Henry, C.S. Paper-based analytical devices for environmental analysis. Analyst 2016, 141, 1874-1887. [CrossRef] [PubMed]

32. Rattanarat, P.; Dungchai, W.; Cate, D.; Volckens, J.; Chailapakul, O.; Henry, C.S. Multilayer Paper-Based Device for Colorimetric and Electrochemical Quantification of Metals. Anal. Chem. 2014, 86, 3555-3562. [CrossRef] [PubMed]

33. Efremov, A.A.; Lokhov, Y.A.; Davydov, A.A. Spectral Characteristics of C=C Bonds in Pi-Complexes of Adsorbed Olefins. React. Kinet. Catal. Lett. 1980, 14, 21-24. [CrossRef]

34. Tsuzuki, W. cis-trans isomerization of carbon double bonds in monounsaturated triacylglycerols via generation of free radicals. Chem. Phys. Lipids 2010, 163, 741-745. [CrossRef] [PubMed]

35. Falade, A.O.; Oboh, G.; Okoh, A.I. Potential Health Implications of the Consumption of Thermally-Oxidized Cooking Oils-A Review. Pol. J. Food Nutr. Sci. 2017, 67, 95-105. [CrossRef]

36. Manic, M.S.; Najdanovic-Visak, V.; da Ponte, M.N.; Visak, Z.P. Extraction of Free Fatty Acids from Soybean Oil Using Ionic Liquids or Poly(ethyleneglycol)s. AIChE J. 2011, 57, 1344-1355. [CrossRef]

(C) 2018 by the authors. Licensee MDPI, Basel, Switzerland. This article is an open access article distributed under the terms and conditions of the Creative Commons Attribution (CC BY) license (http:/ / creativecommons.org/licenses/by/4.0/). 